\title{
Article
}

\section{When Friends Behave Badly: Loneliness and Children's Expectations of Friends and Responses to Transgressions}

Nowland, Rebecca, Balmer, D and Qualter, Pamela

Available at https://clok.uclan.ac.uk/29057/

Nowland, Rebecca orcid iconORCID: 0000-0003-4326-2425, Balmer, D and Qualter, Pamela (2019) When Friends Behave Badly: Loneliness and Children's Expectations of Friends and Responses to Transgressions. British Journal of Developmental Psychology, 37 (4). pp. 551-570. ISSN 0261-510X

It is advisable to refer to the publisher's version if you intend to cite from the work. http://dx.doi.org/10.1111/bjdp.12296

For more information about UCLan's research in this area go to http://www.uclan.ac.uk/researchgroups/ and search for <name of research Group>.

For information about Research generally at UCLan please go to http://www.uclan.ac.uk/research/

All outputs in CLoK are protected by Intellectual Property Rights law, including Copyright law. Copyright, IPR and Moral Rights for the works on this site are retained by the individual authors and/or other copyright owners. Terms and conditions for use of this material are defined in the policies page. 
When Friends Behave Badly: Loneliness and Children's Expectations of Friends and Responses to Transgressions

${ }^{* 1}$ Nowland R. A, ${ }^{2}$ Balmer, D., \& ${ }^{3}$ Qualter, P.

Author Accepted Manuscript

Reference: Nowland, R., Balmer, D. \& Qualter, P. (in press). When Friends Behave Badly: Loneliness and Children's Expectations of Friends and Responses to Transgressions, British Journal of Developmental Psychology

This is the author accepted manuscript. It is advisable to refer to the publisher's version of the paper if you intend to cite from the work. 


\section{Statement of Contribution}

What is already known on the subject:

- Friendships buffer children from loneliness, but some remain lonely despite having friends

- Loneliness has been associated with poor quality friendships

- But there is no examination of why children remain lonely when they have friends

\section{What the present study adds:}

- Lonely children over-emphasis friendship qualities that help to maintain the relationship.

- Loneliness was linked to expectations of being friends with less popular and wellliked peers.

- Lonely children placed less blame on their friends when they violated friendship expectations. 


\begin{abstract}
Previous research has shown that friendships buffer against loneliness, but some children remain lonely despite having best friends. The current study examines relationships between loneliness and friendship functions, expectations, and responses to friendship transgressions in children with best friends (8-11 years; $N=177)$. Children completed questionnaires that measured loneliness, fulfilment of friendship functions, friendship expectations, and the Transgressions of Friendship Expectations Questionnaire (MacEvoy \& Asher, 2012). Findings in the current study showed that loneliness was associated with lower friendship expectations and higher reliable alliance in existing best friendships. Loneliness was also associated with lower sadness and lower perceptions of feeling controlled and devalued by their friend when they transgress. Thus, children with best friends experiencing high loneliness may be more permissiveness of friendship transgressions and may need support to ensure that they do not allow their friends to be unfair to them.
\end{abstract}

Key words: loneliness, friendship, friendship functions, friendship quality, friendship expectations, transgressions. 
Social connections are fundamental for our health and well-being (Baumeister \& Leary, 1995; Sarason, Sarason \& Gurung, 2001); when those social connections do not meet our desired needs, we experience the unpleasant state of loneliness (Perlman \& Peplau 1981). Friendships are particularly important, with close friendships buffering against feelings of loneliness. But loneliness is not always associated with social isolation or a lack of friendships; some children experience loneliness despite having best friends (Parker \& Asher, 1993; Qualter \& Munn, 2002; 2005). Those findings highlight the subjective nature of loneliness: even when a child has close friendships that appear to offer effective social support, they may still report feeling disconnected from others. Reasons for children remaining lonely despite having a best friend have yet to be established. Loneliness has been associated with self-blaming and low self-worth (Anderson, 1999; Galanaki \& Kalantzi-Azizi, 1999, Qualter et al., 2013; Qualter et al., 2015) and may impact on how a person perceives and interprets their friend's behaviour, particularly when their friend is unkind to them. If this is the case, loneliness may result in children having friendships with others who offer them poor quality friendships. There is some literature that has examined associations between loneliness, friendship expectations, and friendship quality (Asher \& Paquette, 2003; Lodder, Scholte, Goossens, \& Verhagen, 2015; MacEvoy, Papadakis, Fedigan, \& Ash, 2016) which shows that loneliness is associated having poorer friendship quality and satisfaction. But there is no empirical examination of associations between loneliness and fulfilment of specific functions and responses to friendship transgressions when a child has a best friend. Such work is important because there may be associations between loneliness, importance placed on specific functions of friends, and ways of dealing with friendship transgressions, which may explain why children remain in friendships that do not make them feel connected. The current study explores the proposal that loneliness may influence the way a child responds to a friend's negative behaviour and is the first to examine associations between loneliness, fulfilment of friendship functions, 
expectations of friendships and responses to violations of those friendships in children with best friends.

\section{The Impact of Loneliness in Childhood}

We all experience bouts of loneliness, but for some people, loneliness can last a long time and be of high intensity (Qualter et al., 2015). When loneliness is experienced in this way in childhood it is associated with poor physical and mental health outcomes (Harris, Robinson \& Qualter, 2013; Qualter et al., 2010; 2013). It is important, then, to examine factors that influence loneliness and explain why children remain lonely, with the aim of preventing long term health issues and to enhance children's immediate quality of life. In contrast to older adults, who can often be socially isolated, loneliness persists in childhood despite children often having many opportunities to interact with others at school or at after school clubs. One might assume that lonely children are also those who are rejected by their peers and are friendless, but that is not always the case: some children who are not rejected by their peers report high levels of loneliness (Parker \& Asher, 1993; Qualter \& Munn, 2002). So, having a friend is not sufficient to buffer loneliness. An open question remains asking why friendship does not reduce loneliness for some children. Establishing the mechanisms involved in the maintenance of childhood loneliness despite having friends is essential in the development of appropriate interventions to reduce loneliness in children.

An important aspect in understanding why some children remain lonely despite having a best friend is in identifying associations between loneliness and perceptions of friends' behaviour and expectations of friendships. Loneliness has been associated with an internal locus of control, self-blaming, low self-worth, rejection sensitivity (Anderson, 1999; Galanaki \& Kalantzi-Azizi, 1999, Qualter et al., 2013; Qualter et al., 2015), and a negative interpretation bias relating to social behaviour (Spithoven, Bijttebier, \& Goossens, 2017). Those specific ways of seeing the social world likely impact how a lonely child perceives others will behave 
towards them and how much blame they place on themselves when a friend is unkind to them. Loneliness may also influence the focus a child places on characteristics of their friendship, favouring functions of friendship that increase the likelihood of retaining the friendship "at all costs" to avoid being friendless.

\section{Loneliness and Friendships}

One reason for children to experience loneliness despite having a friend is whether the friendship is simply a poor quality one. Previous studies examining relationships between loneliness and friendships using overall measures of friendship satisfaction have shown that loneliness is associated with poor quality friendships (Asher \& Paquette, 2003; Lodder et al., 2015; MacEvoy et al., 2016). Further, loneliness has also been associated with lower expectations of friendships (MacEvoy et al., 2016), so it is possible that loneliness is experienced by children with friends when they have lower expectations of that child's behaviour, indicating a poor quality friendship. But why do children have friendships that are poor quality ones that do not buffer them from the experience of loneliness?

Given that loneliness has been associated with low self-worth, self-blaming, and negative biases, it is possible that loneliness may influence the way in which children value particular aspects or functions that their best friendship performs. To date, no studies have examined fulfilment of specific friendship and associations with loneliness when a child has a best friend. Friendship functions relate to the provision of social, emotional, and instrumental resources by one's friend. Mendelson and Aboud (1999) propose that there are six functions performed by a friendship: stimulating companionship (spending time with their friend that results in feelings of enjoyment); help (providing assistance and advice to meet the individual's needs and goals); intimacy (providing an environment where personal thoughts and feelings can be expressed safely); reliable alliance (continuing loyalty of their friend and likelihood to maintain the friendship); self-validation (being encouraging and reassuring and helping to 
validate ones' self-worth); and emotional security (the provision of comfort provided by the friend in novel and/or frightening situations). It is possible that loneliness is associated with valuing functions that help to maintain the relationship (i.e. reliable alliance), rather than functions that improve the quality or intimacy of the relationship (i.e. emotional security). Experiencing loneliness may result in a desire to remain in an existing friendship if those functions are "sufficient" in that friendship, despite other aspects of the friendship being of poor quality. Specifically, reliable alliance may be associated with loneliness because loyalty and likelihood of their friend choosing to remain in the friendship may be preferred by a lonely child because they may fear rejection (Qualter et al., 2013; Spithoven et al., 2017) and want to avoid being friendless. Alternatively, when a child favours friends who are most likely to remain in a friendship with them over other friendship characteristics that promote a quality friendship, they may remain in a poor quality friendship which could lead to feelings of loneliness.

\section{Loneliness and Response to Friendship Transgressions}

A further reason for children remaining lonely despite having friends may relate to their responses when their friend is unkind to them. Things are not always positive in friendships: conflicts arise and, sometimes, friends do not behave in a way that we would expect them to. When a friend is unkind a child can choose to respond negatively, be angry and seek revenge, or be aggressive towards their friend, placing the blame on them. Alternatively, they may choose to overlook the transgression and/or forgive their friend. The negative cognitive bias associated with loneliness may lead them to engender a permissiveness of friendship transgressions and promote negative expectations of friendships. To date there are no studies that have examined associations between loneliness and violations of friendship expectations. Lonely people perceive their social environment as more threatening (Bangee et al., 2015; Qualter et al., 2013; Vanhalst, Gibb \& Prinstein, 2015), have an expectation that their 
social interactions will be negative (Duck, Pond \& Leatham, 1994; Jones, Freemon, \& Goswick, 1981; Jones, Sansone, \& Helm, 1983), and behave passively in social situations, retreating from social interactions when possible (Duck et al., 1994; Jones et al., 1981; Jones, et al., 1983). That research explains why loneliness is associated with lower friendship expectations (i.e. they expect more negative behaviour from friends) and suggests loneliness may be associated with behaving in a passive way within friendships; being more permissiveness of friendship transgressions. Given that loneliness has been associated with passivity and self-blaming in relation to social interaction (Qualter et al., 2015), it may be that loneliness is further associated with passivity when a friend violates friendship expectations, because a child experiencing loneliness may take more of the blame and choose to remain in the friendship despite unkind behaviour from their friend. If loneliness is associated with a passivity and permissiveness when a friend behaves in an unkind way, this may be one reason why children remain in poor quality friendships despite feeling lonely.

Loneliness may also impact on the ways in which children behave when they have high expectations of their friendship and their friend violates those expectations. Although, it is yet to be empirically examined, it is likely that where children have higher expectations of their friends they may experience greater negative response and blaming of their friends when they violate those high expectations. In contrast, where children have a friendship which is highly performing or a high quality one, the friendship transgression may come as a surprise and they may experience heightened sadness, but be more likely to overlook the transgression and/or work towards solving the conflict, forgiving their friend for their unkind behaviour. We have suggested that loneliness may also influence desires to remain in a friendship, so it may moderate the association between high friendship expectations and negative responses to friendship transgressions, resulting in an increased likelihood to forgive their friend's transgression. In the current study, we examine relationships between loneliness and responses 
to friendship violations, but also examine relationships between fulfilment of friendship functions and expectations and responses to friendship transgressions and explore the impact of loneliness on those relationships.

\section{Gender Differences in Friendships}

When examining children's friendships it is important to examine whether any gender differences are evident because gender differences relating to friendships have been found in the research literature. Interacting in larger social groups is more important for boys than girls, with girls more orientated towards dyadic friendships, tending to be more caring and intimate with their friends than boys (Parker \& Asher, 1993; Rose \& Rudolph, 2006), indicating that friendships may perform different functions for boys and girls. In relation to friendship expectations, girls have higher expectations for symmetrical reciprocity and communion, whereas boys have higher expectations for agency (Hall, 2011). The ways in which girls and boys respond to a friendship transgressions and conflicts with a friend are also different. Studies show that boys are more likely to choose revenge and behave more aggressively; girls are more likely to behave non-aggressively and attempt to repair their friendship when there is a conflict (Crick \& Grotpeter, 1995; Rose and Asher, 1999). More recently, MacEvoy and Asher (2012) found that girls were just as likely as boys to report revenge and aggressive behaviour when a friend transgresses. The differences in the studies may relate to different focuses, earlier studies have examined gender differences in responses to conflicts with friends, whereas, MacEvoy and Asher examined responses where a friend had clearly violated the child's expectations. The differences in the results may also represent a cohort effect or may reflect changes in how boys and girls are socialised in modern society in relation to physical aggression. In relation to loneliness, a recent meta-analysis revealed that there are not gender differences in levels of loneliness. In the current study gender may impact the association between loneliness and fulfilment of friendship functions and responses to friendship 
transgressions. In order to address this in the current study we explored gender differences in our preliminary analyses, including gender in further analyses where relevant.

\section{The Current Study}

The current study is the first to examine whether loneliness among children with best friends is associated with fulfilment of specific friendship functions and passivity in responses to violation of friendship expectations.

We examine the following research questions:

1) Is loneliness associated with overall friendship quality and fulfilment of specific friendships functions?

2) Is loneliness associated with lower levels of friendship expectation?

3) Is loneliness, friendship quality and friendship expectation associated with responses to friendship transgressions?

4) Is higher friendship functioning associated with more sadness, strategies to maintain the relationship (i.e. denial, problem solving) and higher forgiveness when their friend transgresses?

5) Does children's loneliness moderate the relationships between friendship expectations and friendship quality and responses to friendship transgression?

Based on previous literature, we predicted that loneliness will be associated with fulfilment of friendship functions that promote the maintenance of the relationship, such as reliable alliance, lower friendship expectations. We also predicted that loneliness would be associated with permissiveness when a friend transgresses (lower negative response to transgression and blaming of their friend) and a motivation to maintain the friendship regardless of such friendship violations. We predict that high expectations of friends would be associated with more negative responses, more aggression, and higher blaming of their friend 
when they violate their expectations (i.e. transgress). In contrast, we predicted that having a highly performing friendship will be associated with higher sadness, higher likelihood of ignoring the transgression or resolving the conflict with the friend and higher forgiveness. Finally, we predict that loneliness will influence the relationship between high friendship expectations and desire to remain in the friendship (i.e. forgiveness of friend).

\section{Method}

\section{Participants}

Children were recruited from years 4,5 and 6 (aged between 8 to 11 years) in two primary schools in the UK. We choose children who were aged 8-11 years because preadolescent friendships have been shown to make important contributions to adolescent (Pedersen, Vitaro, Barker, \& Borge, 2007) and adult social adjustment (Fullerton \& Uranso, 1994). Letters regarding the study were sent to parents prior to data collection. Parents were required to opt out of the study if they did not wish their children to take part $(n=2)$. Two hundred and ten children were recruited and gave verbal consent to take part on the data collection days. Thirteen children were not included in the analyses because they had not complete one or more of the measures due to time restrictions and/or were involved in other scheduled activities in the school. The final sample included 197 children $\left(M_{\text {age }}=9.55, S D=\right.$ $0.90,50 \%$ male). Children were asked if they had a best friend using the following question in the questionnaire distributed to participants "Do you have a best friend" and responded either "yes" or "no". The majority of children who took part in the study reported that they had a best friend $(89.8 \%, n=177)$; eight children did not answer the question. There were no differences in loneliness scores between children who reported having a best friend and those who did not $(t(187)=0.83, p=.407)$. Because we were interested in loneliness experienced when children have a best friend we removed children from the analyses who reported they did not have a best friend or who did not answer the question. This resulted in the removal of 20 
children; the remaining 177 children who reported having a best friend $\left(M_{\mathrm{age}}=9.52, S D=0.87\right.$, $51 \%$ male) were included in the analyses.

\section{Measures}

\section{Loneliness.}

The peer loneliness subscale of the 'Loneliness and Aloneness Scale for Children and Adolescents' (LACA, Marcoen \& Goossens, 1987) was used. This subscale is a 12-item measure and is widely used in loneliness literature with children. Example items are "I think I have fewer friends than others" and "Ifeel isolated from other people". All items are measured on a 4-point scale ranging from 1 (never) to 4 (often). Scores range from 12-48, with higher scores indicating higher levels of loneliness. In the present study the LACA demonstrated a high level of reliability (see Table 1).

\section{Fulfilment of friendship functions.}

The McGill Friendship Functions Questionnaire (Mendelson \& Aboud, 2012) assesses the degree to which a friend fulfils 6 distinct friendship functions. This is a 30 -item measure, with 6 subscales based on the following functions of friendships: stimulating companionship, help, intimacy, reliable alliance, self- validation and emotional security. Example items include “__ is fun to sit and talk with" (stimulating companionship), “__helps me when I need it” (help), “__ is easy to talk to about private things" (intimacy), “__ would stay my friend even if we argued" (reliable alliance), “__ makes me feel special”(Self-validation), “__would make me feel better if I were worried" (emotional security). Participants respond on a 9-point scale $(0=$ never; $8=$ always $)$. The child is asked to imagine that the blank space in each item contains their friend's name, and with them in mind, to respond how often the item applies to their friend on an 8-point scale, from 0 (never) to 8 (always). Each of the Friendship Functions subscales demonstrated acceptable reliability (see Table 1). Similar to previous studies (Brout et al., 2007; Brout, Wood 
\& Pratt, 2009; Mendelson \& Kay, 2003; Morry \& Kitto, 2009), the mean of each sub-scale was computed (ranging from 0-8) and summed to create a total friendship functions measure. Total Friendship Functions scores range from 0 to 48, with higher scores indicating higher friendship functioning. In the present study the McGill Friendship Functions Questionnaire subscales and total Friendship Functions score demonstrated a high level of reliability (see Table 1).

\section{Friendship expectations.}

Hall's (2012) dimensions of ideal expectations were used to measure children's expectations of friendships. Although the questionnaire is designed for young adults, Hall has suggested that it could be used for children if reworded appropriately (Hall, 2012). The measure consists of six factors: symmetrical reciprocity, agency, enjoyment, instrumental aid, similarity and communion. Two items (with the highest factor loadings) were chosen from each of the six factors (i.e. a total of 12 items). Each item was edited so that they were appropriate for children. Editing of the items was only minor and involved amendment to only 3 of the items: "Is physically attractive" was changed to "Is good looking", "Is athletic" to "Likes playing/is athletic" and "Has an exciting personality" to "Is exciting". The specific items used in the current study are in Appendix 1. Children were asked to read a short imaginary story about a new boy/girl who had been placed in their class and were asked to rate how each statement was most important for them to choose to be the child's friend by using a 5-point scale ranging from 1 (not at all important) to 5 (very important). Scores for each item were summed to create a total Friendship Expectations score, ranging from 12 to 60, with higher scores indicating higher expectations. In the present study the dimensions of ideal expectations scale demonstrated a high level of reliability (see Table 1).

\section{Response to friendship transgressions.}


The Transgressions of Friendship Expectations Questionnaire (MacEvoy \& Asher, 2012) was used to assess how children reacted when a friend violates friendship expectations. There are four categories, depicting four friendship transgressions (betrayal, failing to provide validation or emotional support, failing to provide instrumental help and being an unreliable partner). The measure consists of sixteen imaginary vignettes (four vignettes for each transgression category) each depicting transgressions. For example:

"One day you are really upset because you got a bad grade on your social studies test. You tell your friend how upset you are about your bad grade. You also tell your friend that you don't want the other kids in your class to find out how poorly you did. Later that day, though, you find out that your friend told a bunch of kids in your class about your bad grade.”

At the end of each vignette children are asked to rate their emotions (i.e. how they would feel after the transgression categorised into the following emotions: angry, sad, neutral), interpretations (i.e. how would interpret their friend's reasons for their behaviour categorised into neutral, control, devalue interpretations), strategies (i.e. strategies they would use to deal with their friend's transgression categorised into aggression, problem-solving, denial) and goals (i.e. goals that they would want following the friend's transgression categorised into revenge, control, relationship maintenance) following the transgression using a 5-point scale (MacEvoy \& Asher, 2012). Mean scores are calculated for each of the emotions, interpretations, strategies and goals, ranging from 1 to 5, with higher scores indicating higher reporting. Three additional items of forgiveness, rumination, and severity were also administered (MacEvoy \& Asher, 2012) to assess the extent the child believed that s/he would ruminate about the transgressions, how severe s/he believed the transgression was, and how much s/he was likely to forgive the person. For those items a 10-point scale is used, ranging from 1 (not at all) to 10 (a lot). This procedure was repeated for each of the four categories of 
transgressions and ratings are summed to give a total score for forgiveness, rumination and severity, ranging from 4-40, with higher scores relating to higher forgiveness, rumination and severity. Due to time constraints and the need to administer the measure alongside the other study variables, we used only half of the vignettes (randomly selecting two each of the transgression categories); suitable vignettes were chosen by the researchers so that all different transgressions were covered. In the present study Transgressions of Friendship Expectations Questionnaire demonstrated moderate to high levels of reliability for each of the ratings (see Table 1).

\section{Procedure}

Children completed the questionnaire in their class groups in their usual school classrooms with support from research assistants in small groups of 4-5 children. Children with any reading difficulties (previously identified by the school teachers) were given one to one assistance with the questionnaire in the same room as their classmates. The children were instructed to complete the questionnaires quietly and not to discuss their answers. The questionnaires for each year group were counterbalanced between classes so that half of the children completed the transgression measure first, and half the children completed the other measures first. In accordance with MacEvoy and Asher's (2012) procedure for the transgression measure, each vignette was read out, and then the children were instructed to answer the questions individually. When everyone had finished each vignette, the next vignette was read out, this was repeated until this measure was completed. The other measures were not read out; however, the children were given verbal instructions of how to complete each measure. The children were instructed to raise their hand if they needed any assistance. 


\section{Results}

\section{Preliminary analyses}

Means and standard deviations for all the study variables are displayed in Table 1. Before conducting our primary analysis, we first examined whether there were any gender differences in the study variables. Independent t-tests revealed no differences between boys and girls on loneliness $(t(175)=1.03, p=.306)$ or friendship expectations $(t(175)=0.93, p=$ $.355)$, but girls reported higher total friendship functions than boys $(t(153.48)=2.38, p=.018)$. Multivariate analysis for friendship function subscales revealed significant differences between boys and girls for specific friendship functions $(F(6,170)=3.74, p=.002$, Wilk's $\Lambda=0.88$, partial $\eta^{2}=.12$ ). Follow-up univariate analyses revealed gender differences for intimacy and emotional security: girls reported higher levels of their friend giving them intimacy $(F(1,176)$ $=13.22, p<.001$, partial $\left.\eta^{2}=.07\right)$ and emotional security $(F(1,176)=11.33, p=.001$, partial $\left.\eta^{2}=.06\right)$ than boys. Given that there were gender differences only for emotional security and intimacy and these differences were small we did not control for gender differences in the analyses relating to friendship functions subscales. Multivariate analysis for the responses to friendship transgressions revealed no significant differences between boys and girls for interpretations $\left(F(3,173)=1.39, p=.248\right.$, Wilk's $\Lambda=0.98$, partial $\left.\eta^{2}=.02\right)$ or goals $(F(3,173)$ $=0.30, p=.824$, Wilk's $\Lambda=1.00$, partial $\eta^{2}=.01$ ), but there were significant differences between boys and girls for emotions $\left(F(3,173)=4.55, p=.004\right.$, Wilk's $\Lambda=0.93$, partial $\eta^{2}=$ $.07)$ and strategies $\left(F(3,173)=3.37, p=.020\right.$, Wilk's $\Lambda=0.95$, partial $\left.\eta^{2}=.06\right)$. Follow-up univariate analyses revealed that girls reported more sadness following a friendship transgression than boys $\left(F(1,175)=5.51, p=.010\right.$, partial $\left.\eta^{2}=.04\right)$ and boys reported using aggression than girls $\left(F(1,175)=4.58, p=.034\right.$, partial $\left.\eta^{2}=.03\right)$. Independent $t$ tests revealed no significant difference between boys and girls for forgiveness $(t(175)=0.51, p=.613)$, severity $(t(175)=0.46, p=.647)$, and rumination $(t(175)=0.24, p=.810)$. Because gender 
differences were found in responses to transgressions we controlled for gender in analyses that examined responses to friendship transgressions only.

Bivariate correlations between loneliness and friendship functions sub-scales are displayed in Table 2. Higher loneliness was associated with reliable alliance only. Bivariate correlations between Friendship Functions (total), Friendship Expectations, loneliness, and responses to friendship transgressions are displayed in Table 3. Higher loneliness was associated with lower friendship expectations, lower perceptions of their friend being controlling or devaluing of them when they transgress, and reporting transgressions as less severe. Friendship functions was associated with greater sadness, and higher use of problemsolving following a friendship transgression. High friendship expectations were associated with being angry following a friendship transgression, assigning more intent to their friend (i.e. controlling and devaluing them), using more aggression, and revenge, rating the transgression as more severe.

\section{Loneliness and Friendship Quality and Fulfilment of Friendship Functions}

To examine whether loneliness was associated with overall friendship quality and fulfilment of specific functions of friendships we conducted a series of a series of regressions. The model assessing the association between loneliness and reliable alliance was significant $(F(1,176)=4.90, p=.028)$. Higher loneliness was associated with higher reliable alliance $(\beta$ $=.17, t=2.21, p=.028)$. All other models were not significant: stimulating companionship $(F(1,176)=1.17, p=.281)$, help $(F(1,176)=0.21, p=.886)$, intimacy $(F(1,176=0.69, p=$ $.490)$, self-validation $(F(1,176)=0.34, p=.560)$, and emotional security $(F(1,176)=0.01, p=$ .906). ${ }^{1}$ In a final model we examined whether loneliness was associated with overall friendship functions; this was not significant $(F(1,176)=0.38, p=.542)$, indicating that there was no

\footnotetext{
${ }^{1}$ Results for intimacy and emotional security subscales are retained when gender was controlled for in the analyses.
} 
association between loneliness and poorer performance of friendship functions (i.e. friendship quality). Because there were gender effects for the overall friendship functions in our preliminary analyses, in a separate analyses we controlled for gender by adding it at the first step in the model and there was no association between loneliness and poorer performance of overall friendship functions that model.

\section{Loneliness and Friendship Expectations}

To examine whether, in this sample, loneliness was associated with lower friendship expectations we conducted a regression analysis with loneliness predicting friendship expectations. The model was significant $(F(1,176)=5.19, p=.024)$, with higher loneliness associated with lower friendship expectations $(\beta=-.17, t=-2.28, p=.024)$.

\section{Loneliness, Friendship Quality, Expectations and Responses to Friendship}

\section{Transgressions}

To examine whether loneliness, friendship functions and friendship expectations were associated with particular responses to friendship transgressions we conducted a series of hierarchical multiple regressions (Table 4). Because we found gender differences in responses to friendship transgressions in our preliminary analyses we entered gender at the first step to control for gender differences. Friendship functions, friendship expectations, and loneliness were then entered at the second step. To examine moderation effects we multiplied the meancentred variables to create two interaction terms: loneliness $\mathrm{x}$ friendship functions and loneliness $\mathrm{x}$ friendship expectations and entered this at the final step. Loneliness was associated with lower levels of sadness and lower perceptions of their friend being controlling and devaluing of them when they violated friendship expectations. High friendships functions were associated with greater sadness. Higher friendship expectations were associated with higher likelihood of negative interpretation of friend's transgression and behaving with aggression and revenge in response. Loneliness moderated the relationship between 
expectations and forgiveness: higher loneliness and higher expectations were associated with higher forgiveness.

\section{Discussion}

To address the question of why children experience loneliness despite having a best friend, we examined associations between loneliness and (1) fulfilment of specific functions of friendships, and (2) permissiveness of friendship transgressions. Findings showed that, within friendships, loneliness was related to greater permissiveness of friends when they violate friendship expectations and having friendships with other children who display more loyalty and/or confidence that they would remain in the friendship despite all odds.

\section{Loneliness and Fulfilment of Friendship Functions}

Using measures of friendship satisfaction, previous empirical work has shown that poor friendship quality is associated with loneliness (Asher \& Paquette, 2003; Lodder et al., 2015). In the current study, we used, instead, a measure of how well the friendship fulfills specific friendship functions. We proposed that loneliness would be associated with fulfilment of friendship functions that enhance the likelihood of retaining that friendship. Loneliness was associated with higher reliable alliance, which refers to the friend showing loyalty and a desire to remain in the friendship at any cost (i.e. despite conflict in their friendship, or even when the child is absent for a long period of time). Reliance alliance to be a particularly important function of the friendship when children are experiencing high loneliness because it protects them from being alone and becoming friendless. Also, loneliness may be associated with choosing a friend that is perceived to be less likely to reject them because loneliness has been associated with a fear of rejection (Qualter et al., 2013), and for lonely children, knowing that their friend, even if other children are rejecting them, will still be their friend may be particularly important. However, given the cross sectional nature of the data in the current 
study, the findings may also be explained in another way. Favouring qualities in a friend that help to retain the friendship regardless of difficulties, could lead to a child remaining in a friendship that is a poor quality one, thus resulting in feelings of loneliness. Future research will need to examine these relationships over time to establish whether loneliness influences preferences for particular characteristics of friendships.

In the current study, there was not a relationship between overall poorer friendship performance and loneliness in children with best friendships. Relationships between loneliness and friendship quality have been found when overall friendship satisfaction measures were used (Asher \& Paquette, 2003; Lodder et al., 2015; MacEvoy, et al., 2016). Thus, loneliness experienced in children with a best friend may not be related to having a poorer performing friendship; loneliness, being a subjective measure, may relate more to satisfaction with the friendship. However, we should remain cautious about that interpretation because only friendship functioning was measured in the current study, so that contrast cannot be made with this data alone. Future studies should use measures of overall friendship satisfaction and fulfilment of friendship functions to explore that proposition. It is important also to note in the current study we only used self-report measures of children's friendships; children's teachers and parents ratings may offer another perspective. Those should be used in future work to determine whether children reporting high loneliness report deficiencies in their friendships, but others do not see those relationship as lacking in any specific ways.

\section{Loneliness and Friendship Expectations}

Replicating previous findings, we found that loneliness was associated with lower expectations about friendships (MacEvoy et al., 2016). What was unique about the current study is that all participants had best friends, so the findings show that the association between loneliness and lower expectations of friendships is retained even when children report having best friends. Thus, having a best friend does not necessarily increase a child's positivity about 
friendships when they experience loneliness. One reason for those children to have lower expectations about friendships is that loneliness is associated with negative biases about relationships (Spithoven et al., 2017). It may be that, because lonely children have negative biases about social relationships and expect negative outcomes, they learn to have lower expectations of close friendships. In addition, lonely children have been shown to (1) have low self-worth (Qualter et al., 2013), so they may expect to be friends with those who are less popular, and, thus, have lower expectations for the friendships that they form, and (2) report lower levels of trust in others (Qualter et al., 2013) so may expect a lot less from others.

There are alternative explanations: It is equally possible that the relationship is the other way around, such that having lower expectations of friendships leads to loneliness. Children who have lower expectations of friends may become friends with those who are less likely to be good friends and/or those who do not have characteristics that enable them to perform the important functions of friendships (i.e. emotional intelligence, kindness). In the current study there was a small association between fulfilment of friendship functions and expectations, indicating that those with higher expectations have better performing friendships. Future studies will need to examine those relationships using longitudinal designs.

\section{Loneliness and Responses to Friendship Transgressions}

There is evidence in the current study that loneliness experienced in children who report having a best friend is linked to permissiveness of friendship transgressions because loneliness was associated with lower sadness and judging their friend's behaviour as less controlling and devaluing. Empirical evidence has revealed that lonely children are more passive, have low self-worth, and non-self-serving attribution styles, blaming themselves for negative outcomes (Anderson, 1999; Galanaki \& Kalantzi-Azizi, 1999, Qualter et al., 2013) and this may explain why loneliness in the current study was associated with placing less blame on their friend for 
their transgression. Because loneliness is associated with self-blaming, it may be that, when a friend transgresses, those with higher loneliness perceive their own incompetence as the cause of their friend's behaviour, rather than viewing the transgression as their friend being "unfair". In this way, lonely children may rate friendship transgressions as less controlling and devaluing, taking on some or all the blame for the transgression themselves. This may, then, result in the lonely child being more accepting of unkind behaviour from their friend, thus, impacting on their feelings of loneliness. Importantly this proposition was not tested in the current study.

A further caution with interpreting the findings is that characteristics of lonely children may not be the only explanation: the cross-sectional nature of our data mean that it is equally possible that being permissive of friendship transgressions leads to loneliness. Certainly, being more permissive of unkind behaviour from a friend could mean that children remain in poor quality friendships that do not buffer them from the experience of loneliness. An examination of relationships over time will be important in understanding the relationship between permissiveness of friendship transgressions and loneliness.

\section{Friendship Expectations and Friendship Quality and Responses to Friendship Transgressions}

Having a high quality friendship was associated with experiencing greater sadness and having high expectations of friendships was associated with experiencing greater anger following a friendship transgression. Thus, expectations of friends or previous experience of a positive friendship may explain negative affect following a friendship transgression. Where a child has positive expectations of their friends they may feel more negative emotions when their friend violates their expectations and is unkind to them. Having high expectations of friends was related to higher forgiveness of their friend and a greater likelihood of ignoring the 
transgression or working towards resolving the conflict. This suggests that children who have high quality friendships are more motivated towards forgiveness of their friend when they violate friendship expectations, possibly because the behaviour is out of character for their friend, who is typically kind to them (i.e. high quality friendship). In contrast, having high expectations of friends was related to lower likelihood of forgiveness and retaliation and aggressive behaviour when a friend violated those expectations. This suggests that when children have higher expectations for their friend's behaviour they are more motivated to behave negatively and terminate the friendship, rather than working towards a resolution that may mean that they can remain in the friendship. What is interesting in the findings is that loneliness moderated the relationship between friendship expectations and forgiveness. Those with high expectations of their friends reported more negative feelings about the violation of their expectations, choosing to be aggressive, seeking revenge, and not wanting to forgive their friend. However, where a child had high expectations of their friends, loneliness was associated with higher likelihood of forgiving their friend. This finding indicates where a child is experiencing loneliness, despite having high expectations for their friend's behaviour, they may allow more violations of friendship expectations, further supporting the proposition that loneliness may be associated with permissiveness of friends' transgressions. Having high expectations for a friend's behaviour and experiencing loneliness despite having a best friend may lead to higher forgiveness of the friend because the child takes on more of the blame for the friendship transgression themselves. They may also fear rejection (Qualter et al., 2013) so choose to forgive their friend, rather than confront them or try to resolve the conflict because this may lead to a rejection by their friend via a termination of the friendship. 


\section{Gender Differences in Responses to Transgressions}

In contrast to MacEvoy and Asher's study, which did not find gender differences in relation to aggression, in the current study, boys reported using aggression as a strategy to deal with friendship transgressions more than girls. Previous studies have obtained similar gender differences in aggressive behaviour in relation to dealing with conflicts (Card, Stucky, Sawalani, \& Little, 2008; Crick \& Grotpeter, 1995; Rose \& Asher, 1999). The result indicates that there may be cohort differences in aggression, likely to be based on differences in parenting and cross-cultural differences in gender socialisation (i.e. MacEvoy and Asher's study was conducted in the US). Similar to MacEvoy and Asher (2012), in the current study, girls reported more sadness than boys. The results are not surprising as gender socialisation may account for girls feeling sad and boys feeling okay (Zeman \& Garber, 2013); that is, boys may not believe that it is acceptable to display feelings of sadness. MacEvoy and Asher found that girls were still ruminating about the transgression one week later, but in the current study, there were no gender differences in rumination, which may also reflect differences at a cohort level.

\section{Applications of the findings}

The findings in the current study indicate that differences in fulfilment of specific friendship functions, expectations of friends, and permissiveness of friendship transgressions may explain why loneliness is experienced in children despite having a best friend. Children with a best friend who experience loneliness may need support to address the way they interpret their friend's behaviour and address the value placed on specific characteristics in their friends (i.e. reliable alliance) over others. Developing strategies to children who experience loneliness despite having a best friend, targeted at understanding what a good friendship entails and helping them to deal appropriately with friendship transgressions will be important. Such 
strategies will help children to have a good quality friendship that buffers their loneliness and avoid them remaining in friendship where a friend is unpleasant to them.

\section{Strengths \& Limitations}

This study is the first to examine associations between loneliness experienced whilst having a best friend, fulfilment of friendship functions, expectations and responses to friendship transgressions and tries to understand why some children experience loneliness despite having a best friend. Findings indicate that loneliness within best friendships is associated with a fulfilment of friendship functions relating to maintenance of the friendship (i.e. loyalty) and greater permissiveness of friendship transgressions. These findings are important because they indicate reasons why children who report having best friend's experience loneliness and offer suggestions of appropriate strategies to support them to develop friendships that do buffer them from the experience of loneliness.

There are some limitations of this study. First, children were instructed to state whether they had a best friend or not but were not asked to write down the name of the person they considered to be their best friend or which friend they had in mind when completing the measures. Thus, we are unaware of whether lonely child's friend reciprocated those friendships and whether the child's best friend rated the friendship in the same way. There was also no measure of numbers of other friends (i.e. not best friends) which may be important because number of friendships may impact the way children perceive their best friends. It could be that the friendship would be perceived as more valuable if the child had fewer friends. It is also possible that where children only had one friendship that they reported them as a best friend, even if it was not a high-quality friendship. Second, the current study involved only self-report measures, so data are children's reports of how they think they would behave in a given situation, rather than observations of actual behaviour. Some children in the study may have been reflecting on actual experiences of friendship transgressions and how they behaved in the 
past and others who had not experienced those types of transgressions imagined how they would behave in that situation. It will be important in future studies to examine actual responses to real life transgressions from friendships, to establish if self-report measures reflect actual behaviour in a real-life transgression. Third, we were not able to examine between group differences (i.e. school and school class) in the data analyses, thus future studies will want to examine whether between group differences are evident in larger samples using hierarchical modelling.

As a first study in this research area, we examined only the association of loneliness with fulfilment of friendship functions, expectations, and responses to transgressions and it is possible that other factors, such as self-esteem, depression, social anxiety and social isolation may also be important influencers of those relationships and interactions with loneliness and responses to friendship transgression. Future studies in this area will need to examine those other factors that may influence friendship transgressions and/or the experience of loneliness. In the current study we focused children who reported having best friendships, but to obtain a more complete picture of friendships, future studies should gather information about children's number of best friends, as well as their number of friends and close friends. We did not examine relationships among lonely children with no friends and it is possible that relationships with peers, particularly relationship transgression, will be different for those children. The study was cross sectional, so we do not know if children increased, decreased, or maintained their loneliness over an extended period, or how friendships changed over time. A longitudinal design for future work in this area would be particularly advantageous as it would enable an examination of selection of friends and influences on friendships over time. We also cannot establish from the current findings whether characteristic behaviour associated with being lonely leads to the permissiveness of friendships (i.e. negative biases) or whether being permissive of friendship transgression leads to loneliness. Future research will want to study 
relationships over the course of the school year to reveal whether children have maintained their friendship, even if they report it to be of poor quality, enabling an examination of loneliness and termination or commencement of friendships.

\section{Conclusion}

The current study examined loneliness, fulfilment of friendship functions, friendship expectations, and responses to friendship transgressions in children reporting having best friends aged 8-11 years. Loneliness in children with best friends was associated with higher reliable alliance in the friendship. Replicating previous findings from existing studies (MacEvoy et al., 2016), in the current study, loneliness experienced in children with best friends was associated with lower friendship expectations. Experiencing loneliness despite having a best friend was associated with placing less blame on friends when they transgress, indicating that loneliness may be associated with greater permissiveness of friendship transgressions. These findings are important because they indicate that children who experience loneliness despite having an existing best friendship may need support to form quality friendships, and reduce their loneliness. 


\section{References}

Anderson, C. A. (1999). Attributional style, depression, and loneliness: A cross-cultural comparison of American and Chinese students. Personality and Social Psychology Bulletin, 25, 482-499. doi:/10.1177\%2F0146167299025004007

Asher, S. R., \& Paquette, J. A. (2003). Loneliness and peer relations in childhood. Current directions in psychological science, 12, 75-78. doi: 10.1111/1467-8721.01233

Baumeister, R. F., \& Leary, M. R. (1995). The need to belong: Desire for interpersonal attachments as a fundamental human motivation. Psychological Bulletin, 117, 497-529. doi: /10.1037/0033-2909.117.3.497

Berndt, T.J. (2002). Friendship quality and social development. American Psychology Society, 11, 7-10. doi: 10.1111/1467-8721.00157

Buote, V. M., Pancer, S. M., Pratt, M. W., Adams, G., Birnie-Lefcovitch, S., Polivy, J., \& Wintre, M. G. (2007). The importance of friends: Friendship and adjustment among 1st-year university students. Journal of Adolescent Research, 22(6), 665689.

Buote, V. M., Wood, E., \& Pratt, M. (2009). Exploring similarities and differences between online and offline friendships: The role of attachment style. Computers in Human Behavior, 25(2), 560-567.

Crick, N.R. \& Grotpeter, J.K. (1995). Relational aggression, gender, and social-psychological adjustment. Child development, 66, 710-722. doi: 10.1111/j.1467-

8624.1995.tb00900.x

Duck, S., Pond. K., \& Leatham, G. (1994). Loneliness and the evaluation of relational events. Journal of Social and Personal Relationships, 11, 253-276. doi: $10.1177 / 0265407594112006$ 
Fullerton, C. S., \& Ursano, R. J. (1994). Preadolescent peer friendships: A critical contribution to adult social relatedness? Journal of Youth and Adolescence, 23(1), 43-63.

Galanaki, E. P., \&, Kalantzi-Azizi, A. (1999). Loneliness and social dissatisfaction: Its relation with children's self-efficacy for peer interaction. Child Study Journal, 2, 1-1. Retrieved from https://www.researchgate.net/publication/258373436

Hall, J.A. (2011). Sex differences in friendship expectations: A meta-analysis. Journal of Social and Personal Relationships, 1-25. doi: 10.1177/0265407510386192.

Hall, J. A. (2012). Friendship standards: the dimensions of ideal expectations. Journal of Social and Personal Relationships, 29, 884-907. doi: 10.1177/0265407512448274.

Harris, R.A ., Qualter, P., \& Robinson, S.J. (2013). Loneliness trajectories from middle childhood to early adolescence: impact on perceived health and sleep disturbance. Journal of Adolescence, 36,1295-1304. doi: 10.1016/j.adolescence.2012.12.009

Jones, W.H., Freemon, J.E., \& Goswick, R.A. (1981). The persistence of loneliness: Self and other determinants. Journal of Personality, 49, 27-48. doi: 10.1111/j.14676494.1981.tb00844.x

Jones, W.H., Sansone, C., \& Helm, B. (1983). Loneliness and interpersonal judgements. Society for Personality and Social Psychology, 9, 437-441. doi: $10.1177 / 0146167283093014$

Lodder, G.M.A., Scholte, R.H.J., Goossens, L., Verhagen, M. (2015). Loneliness in early adolescence: Friendship quality, and dyadic processes. Journal of Clinical Child \& Adolescent Psychology, 00, 1-12. doi:10.1080/153744162015.1070352

MacEvoy, J. P., \& Asher, S. R. (2012). When friends disappoint: Boys' and girls' responses to transgressions of friendship expectations. Child development, 83, 104-119. doi: 10.1111/j.1467-8624.2011.01685.x 
MacEvoy, J. P., Papadakis, A. A., Fedigan, S. K., \& Ash, S. E. (2016). Friendship Expectations and Children's Friendship-Related Behavior and Adjustment. Merrill-Palmer Quarterly, 62, 74-104. Retrieved December 2, 2017, from Project MUSE database.

Marcoen, A., Goossens, L., \& Caes, P. (1987). Loneliness in pre-through late adolescence: exploring the contributions of a multidimensional approach. Journal of Youth and Adolescence, 16, 561-577. doi:10.1007/bf02138821

Mendelson, M. J., \& Aboud, F. (2012). McGill Friendship Questionnaire \& Friendship Functions (MFQ-FF). Measurement instrument database for the social science. Retrieved fromhttps://www.midss.org

Mendelson, M. J., \& Kay, A. C. (2003). Positive feelings in friendship: Does imbalance in the relationship matter? Journal of Social and Personal Relationships, 20(1), 101-116.

Morry, M. M., \& Kito, M. (2009). Relational-interdependent self-construal as a predictor of relationship quality: The mediating roles of one's own behaviors and perceptions of the fulfilment of friendship functions. The Journal of social psychology, 149(3), 305-322.

Parker, G.J., \& Asher, S. R. (1993). Friendship and friendship quality in middle childhood: links with peer group acceptance and feelings of loneliness and social dissatisfaction. Developmental Psychology, 2, 611-621. doi: 10.1037/00121649.29.4.611

Pedersen, S., Vitaro, F., Barker, E. D., \& Borge, A. I. (2007). The timing of Middle- Childhood peer rejection and friendship: Linking early behavior to Early- Adolescent adjustment. Child development, 78(4), 1037-1051. 
Perlman, D., \& Peplau, L. A. (1981). Toward a Social Psychology of Loneliness. In R. Gilmour, \& S. Duck (Eds.), Personal Relationships: 3. Relationships in Disorder (pp. 3156). London: Academic Press.

Qualter, P., Brown, S. L., Rotenberg, K. J., Vanhalst, J., Harris, R. A., Goossens, L., ... \& Munn, P. (2013). Trajectories of loneliness during childhood and adolescence: Predictors and health outcomes. Journal of Adolescence, 36, 1283-1293. doi: /10.1016/j.adolescence.2013.01.005

Qualter, P., \& Munn, P. (2002). The separateness of social and emotional loneliness in childhood. Journal of Child Psychology and Psychiatry, 43, 233-244. doi:10.1111/1469-7610.00016

Qualter, P., Rotenberg, K., Barrett, L., Henzi, P., Barlow, A., Stylianou, M., \& Harris, R. A. (2013). Investigating hypervigilance for social threat of lonely children. Journal of Abnormal Child Psychology, 41(2), 325-338. doi: 10.1007/s10802-012-9676$\mathrm{X}$

Qualter, P., Vanhalst, J., Harris, R., Van Roekel, E., Lodder, G., Bangee, M., ... \& Verhagen, M. (2015). Loneliness across the life span. Perspectives on Psychological Science, 10, 250-264. doi:/10.1177\%2F1745691615568999

Rose, A. J., \& Asher, S. R. (1999). Children's goals and strategies in response to conflicts within a friendship. Developmental psychology, 35, 69.

Rose, A. J., \& Rudolph, K. D. (2006). A Review of Sex Differences in Peer Relationship Processes: Potential Trade-offs for the Emotional and Behavioral Development of Girls and Boys. Psychological Bulletin, 132, 98-131. doi: 10.1037/0033290.132.1.98

Rotenberg K.J. (1991) The Trust-Value Basis of Children's Friendship. In: Rotenberg K.J. (eds) Children's Interpersonal Trust. Springer, New York, NY 
Sarason, B. R., Sarason, I. G., \& Gurung, R. A. R. (2001). Close Personal Relationships and Health Outcomes: A Key to the Role of Social Support. In B. Sarason, \& S. Duck (Eds.), Personal Relationships: Implications for Clinical and Community Psychology (pp. 15-41). West Sussex, England: Wiley.

Spithoven, A. W., Bijttebier, P., \& Goossens, L. (2017). It is all in their mind: A review on information processing bias in lonely individuals. Clinical Psychology Review, 58, 97-114. doi: /10.1016/j.cpr.2017.10.003

Vanhalst, J., Luyckx, K., Raes, F., \& Goossens, L. (2012). Loneliness and depressive symptoms: The mediating and moderating role of uncontrollable ruminative thoughts. The Journal of psychology, 146(1-2), 259-276.

Zawadzki, M. J., Graham, J. E., \& Gerin, W. (2013). Rumination and anxiety mediate the effect of loneliness on depressed mood and sleep quality in college students. Health Psychology, 32(2), 212. 


\section{Appendix 1}

Friendship Expectations:

1. Cheer me up when I am sad

2. When others are mean to me they will stand up for me

3. Somebody who likes playing/athletic

4. Is good looking

5. Likes the same things as me

6. Having similar ideas and opinions

7. Makes me laugh

8. Is exciting

9. Does favours for me

10. Helps me to complete jobs or tasks

11. Be someone with whom I can share secrets

12. Could talk to this person about my personal problems 
Table 1.

Mean and standard deviations for all study variables by gender

\begin{tabular}{|c|c|c|c|c|c|c|}
\hline & & & & & $\mathrm{Bc}$ & \\
\hline & Range & $\begin{array}{c}\text { Reliability } \\
\text { Co-efficient }(\alpha)\end{array}$ & $M$ & $S D$ & $M$ & $S D$ \\
\hline Peer Loneliness & $12-48$ & .81 & 36.65 & 6.31 & 35.57 & 7.70 \\
\hline Friendship Functions & $0-40$ & .93 & 42.33 & 4.97 & 40.16 & 6.92 \\
\hline Stimulating & $0-8$ & .73 & 7.23 & 0.93 & 7.05 & 1.20 \\
\hline companionship & & & & & & \\
\hline Help & $0-8$ & .71 & 6.77 & 1.15 & 6.25 & 1.59 \\
\hline Intimacy & $0-8$ & .72 & 7.15 & 1.03 & 6.27 & 1.77 \\
\hline Reliable alliance & $0-8$ & .81 & 7.32 & 1.02 & 7.03 & 1.27 \\
\hline Self- validation & $0-8$ & .78 & 6.78 & 1.09 & 6.40 & 1.48 \\
\hline Emotional security & $0-8$ & .79 & 7.12 & 0.89 & 6.32 & 1.67 \\
\hline Friendship Expectations & $12-60$ & .82 & 41.53 & 8.26 & 42.75 & 9.26 \\
\hline Responses to Transgress & & & & & & \\
\hline Emotional Response & & & & & & \\
\hline Emotion Angry & $1-5$ & .83 & 3.54 & 1.08 & 3.72 & 1.00 \\
\hline Emotion Sad & $1-5$ & .74 & 4.17 & 0.79 & 3.82 & 1.01 \\
\hline Emotion Okay & $1-5$ & .85 & 1.73 & 0.76 & 1.83 & 0.68 \\
\hline Interpretations & & & & & & \\
\hline Neutral & $1-5$ & .81 & 2.94 & 1.03 & 2.96 & 1.03 \\
\hline Control & $1-5$ & .87 & 2.61 & 1.17 & 2.70 & 1.14 \\
\hline Devalue & $1-5$ & .88 & 2.77 & 1.12 & 2.59 & 1.11 \\
\hline Strategies & & & & & & \\
\hline Problem-Solve & $1-5$ & .86 & 3.60 & 1.02 & 3.51 & 1.16 \\
\hline Denial & $1-5$ & .85 & 2.03 & 1.08 & 2.93 & 1.17 \\
\hline Aggression & $1-5$ & .90 & 2.17 & 0.93 & 3.71 & 1.08 \\
\hline Goals & & & & & & \\
\hline Relationship & $1-5$ & .88 & 3.76 & 0.68 & 3.78 & 0.85 \\
\hline Revenge & $1-5$ & .90 & 2.17 & 1.18 & 2.29 & 1.16 \\
\hline Control & $1-5$ & .89 & 3.56 & 1.13 & 3.71 & 1.11 \\
\hline Forgiveness & $4-40$ & .87 & 26.82 & 7.52 & 26.20 & 8.52 \\
\hline Severity & $4-40$ & .79 & 29.89 & 5.81 & 29.45 & 6.70 \\
\hline Rumination & $4-40$ & .85 & 22.05 & 9.21 & 22.38 & 9.10 \\
\hline
\end{tabular}


LONELINESS AND FRIENDSHIP TRANSGRESSIONS

Table 2.

Bivariate correlations between loneliness and friendship functions subscales

\begin{tabular}{lcc}
\hline & $r$ & $p$ \\
\hline Simulating companionship & .08 & .281 \\
Help & -.01 & .890 \\
Intimacy & .05 & .490 \\
Reliable alliance & .17 & .028 \\
Self-validation & -.04 & .560 \\
Emotional security & .01 & .906 \\
\hline
\end{tabular}


LONELINESS AND FRIENDSHIP TRANSGRESSIONS

Table 3.

Bivariate correlations between study variables

\begin{tabular}{|c|c|c|c|c|c|c|c|c|c|c|c|c|c|c|c|c|c|}
\hline & 2 & 3 & 4 & 5 & 6 & 7 & 8 & 9 & 10 & 11 & 12 & 13 & 14 & 15 & 16 & 17 & 18 \\
\hline 1.UCLA & .05 & $-.17 *$ & -.13 & -.14 & .10 & .10 & $-.18^{*}$ & $-.18^{*}$ & .02 & .14 & -.08 & -.11 & -.03 & .06 & .01 & $-.15 *$ & -.02 \\
\hline 2.FF & & $.16^{*}$ & -.03 & $.19 *$ & -.08 & .10 & .08 & .09 & $.16 *$ & .13 & -.09 & -.10 & .10 & .13 & .13 & $<.01$ & -.01 \\
\hline 3.FE & & & $.21 *$ & .13 & .02 & -.11 & $.20^{*}$ & $.23 *$ & -.11 & .02 & $.18^{*}$ & $.18^{*}$ & .02 & -.06 & -.12 & $.21 *$ & .10 \\
\hline 4. EMOT-Angry & & & & $.41 * *$ & $-.33 * *$ & $-.39 * *$ & $-.51 * *$ & $.46 * *$ & $-.18 *$ & $-.31 * *$ & $.50 * *$ & $.44 * *$ & $.36 * *$ & -.02 & $-.40 * *$ & $.48 * *$ & $.24 *$ \\
\hline 5.EMOT- Sad & & & & & $-.54 *$ & -.12 & $.36^{* *}$ & $.37 * *$ & .11 & -.05 & $.16^{*}$ & .13 & $.43 * *$ & $.17 *$ & -.05 & $.54 * *$ & $.16^{*}$ \\
\hline 6. EMOT- Okay & & & & & & $.20 *$ & $-.23 *$ & $-.22 *$ & .09 & .15 & $-.15^{*}$ & -.10 & $-.38 * *$ & $<.01$ & $.24 *$ & $-.37 * *$ & $-.16^{*}$ \\
\hline 7. INT - Neutral & & & & & & & $-.44 * *$ & $-.60 * *$ & $.59 * *$ & $-.59 * *$ & $-.52 * *$ & $.32 * *$ & -.13 & $.51^{* *}$ & $.66^{* *}$ & $-.28 * *$ & .03 \\
\hline 8. INT - Control & & & & & & & & $.66 * *$ & $-.32 * *$ & $-.33 * *$ & $-.57 * *$ & $.46 * *$ & $.48 * *$ & $-.18^{*}$ & $-.48 * *$ & $.57 * *$ & $<.01$ \\
\hline 9. INT - Devalue & & & & & & & & & $-.49 * *$ & $-.45^{* *}$ & $.68 * *$ & $.49 * *$ & .30 ** & $-.31 * *$ & $-.60^{* *}$ & $.54 * *$ & -.02 \\
\hline 10.STR - PS & & & & & & & & & & $.66^{* * *}$ & $-.62 * *$ & $-.41 * *$ & -.03 & $.73 * *$ & $.72 * *$ & $-.15^{*}$ & .05 \\
\hline 11. STR - Denial & & & & & & & & & & & $-.48 * *$ & $-.29 * *$ & -.06 & $.61 * *$ & $.63 * *$ & $-.25 * *$ & -.08 \\
\hline 12.STR - Aggress & & & & & & & & & & & & $.72 * *$ & $.30 * *$ & $-.36 * *$ & $-.68 * *$ & $.43 * *$ & -.05 \\
\hline 13.GL - Revenge & & & & & & & & & & & & & $.28 * *$ & $-.18^{*}$ & $-.41 * *$ & $.31 * *$ & .13 \\
\hline 14.GL - Control & & & & & & & & & & & & & & $.25^{*}$ & $-.24 *$ & $.40 * *$ & -.01 \\
\hline $\begin{array}{l}\text { 15. GL - Rel } \\
\text { 16. Forgiveness }\end{array}$ & & & & & & & & & & & & & & & $.58 * *$ & $\begin{array}{l}-.03 \\
-.34 * *\end{array}$ & $\begin{array}{r}<.01 \\
.12\end{array}$ \\
\hline 17.Severity & & & & & & & & & & & & & & & & & .13 \\
\hline 18.Rumination & & & & & & & & & & & & & & & & & \\
\hline
\end{tabular}

18.Rumination

Note. UCLA = Loneliness, FF = Friendship Functions, FE = Friendship Expectations, EMOT-Angry = angry emotional response, EMOT - Sad $=$ Sad emotional response, EMOT - okay $=$ okay emotional response, INTNeutral $=$ Neutral interpretation, INT - Control $=$ control interpretation, INT - Devalue $=$ Devalue interpretation, STR - PS $=$ problem-solving strategy, STR - Denial $=$ Denial Strategy, STR - Agress $=$ Aggression

Strategy, GL - Revenge $=$ revenge goal, GL - Control $=$ control goal, GL - Rel $=$ relationship goal, $* * p<.001, * p<.05$ 


\section{LONELINESS AND FRIENDSHIP TRANSGRESSIONS}

Table 4.

Multiple regression with Friendship functions, expectations and responses to transgressions as predictors of loneliness

\begin{tabular}{|c|c|c|c|c|c|c|c|c|c|c|c|c|}
\hline & \multicolumn{6}{|c|}{ Emotions } & \multicolumn{6}{|c|}{ Interpretation } \\
\hline & \multicolumn{2}{|c|}{ Angry } & \multicolumn{2}{|c|}{$\mathrm{Sad}$} & \multicolumn{2}{|c|}{ Okay } & \multicolumn{2}{|c|}{ Neutral } & \multicolumn{2}{|c|}{ Control } & \multicolumn{2}{|c|}{ Devalue } \\
\hline & $\Delta R^{2}$ & $\beta$ & $\Delta R^{2}$ & $\beta$ & $\Delta R^{2}$ & $\beta$ & $\Delta R^{2}$ & $\beta$ & $\overline{\Delta R^{2}}$ & $\beta$ & $\Delta R^{2}$ & $\beta$ \\
\hline Step 1 & .01 & & $.04 *$ & & .01 & & $<.01$ & & $<.01$ & & $<.01$ & \\
\hline Gender & & -.09 & & $.19 *$ & & -.07 & & -.01 & & -.04 & & .08 \\
\hline Step 2 & $.05^{*}$ & & $.06^{*}$ & & .02 & & .03 & & $.06^{* *}$ & & $.08^{* *}$ & \\
\hline $\mathrm{FF}$ & & -.04 & & $.15^{*}$ & & -.09 & & .12 & & .06 & & .04 \\
\hline FE & & $.20^{*}$ & & .10 & & .05 & & -.12 & & $.16^{*}$ & & $.20 * *$ \\
\hline UCLA & & -.09 & & $-.15^{*}$ & & .11 & & .08 & & $-.16^{*}$ & & $-.15^{*}$ \\
\hline Step 3 & .01 & & $<.01$ & & .01 & & $<.01$ & & $<.01$ & & .01 & \\
\hline $\begin{array}{l}\text { UCLA x } \\
\text { FF }\end{array}$ & & -.05 & & -.03 & & .05 & & $<-.01$ & & $<-.01$ & & .05 \\
\hline $\begin{array}{l}\text { UCLA } x \\
\text { FE }\end{array}$ & & -.09 & & .03 & & .04 & & .03 & & -.04 & & .10 \\
\hline \multirow[t]{4}{*}{ Total $R^{2}$} & \multicolumn{2}{|c|}{$.07 *$} & \multicolumn{2}{|c|}{$.10^{* *}$} & \multicolumn{2}{|c|}{.03} & \multicolumn{2}{|c|}{.04} & \multicolumn{2}{|c|}{$.07^{\#}$} & \multicolumn{2}{|c|}{$.10^{* *}$} \\
\hline & \multicolumn{6}{|c|}{ Strategies } & \multicolumn{6}{|c|}{ Goals } \\
\hline & \multicolumn{2}{|c|}{ Denial } & \multicolumn{2}{|c|}{ Problem solve } & \multicolumn{2}{|c|}{ Aggression } & \multicolumn{2}{|c|}{ Revenge } & \multicolumn{2}{|c|}{ Control } & \multicolumn{2}{|c|}{ Relationship } \\
\hline & $\Delta R^{2}$ & $\beta$ & $\Delta R^{2}$ & $\beta$ & $\overline{\Delta R^{2}}$ & $\beta$ & $\Delta R^{2}$ & $\beta$ & $\Delta R^{2}$ & $\beta$ & $\overline{\Delta R^{2}}$ & $\beta$ \\
\hline Step 1 & .01 & & $<.01$ & & $.03 *$ & & $<.01$ & & $<.01$ & & $<.01$ & \\
\hline Gender & & -.07 & & .04 & & $-.16^{*}$ & & -.06 & & -.06 & & -.01 \\
\hline Step 2 & .04 & & $.05^{*}$ & & .04 & & $.05^{*}$ & & .01 & & .03 & \\
\hline FF & & $.16^{*}$ & & $.19^{*}$ & & -.10 & & -.13 & & .12 & & .15 \\
\hline $\mathrm{FE}$ & & -.04 & & -.15 & & $.18^{*}$ & & $.19^{*}$ & & -.01 & & -.09 \\
\hline UCLA & & -.14 & & -.02 & & -.03 & & -.07 & & -.03 & & .04 \\
\hline Step 3 & $<.01$ & & .02 & & .02 & & .01 & & .01 & & .02 & \\
\hline $\begin{array}{l}\text { UCLA x } \\
\text { FF }\end{array}$ & & -.04 & & -.12 & & .03 & & -.08 & & -.08 & & -.10 \\
\hline $\begin{array}{l}\text { UCLA } x \\
\text { FE }\end{array}$ & & .02 & & .15 & & -.15 & & -.08 & & .03 & & .15 \\
\hline \multirow[t]{3}{*}{ Total $R^{2}$} & & & & & & & $.07^{*}$ & & & & & \\
\hline & For & & & & & & & & & tion & & \\
\hline & $\Delta R^{2}$ & $\beta$ & & & $\overline{\Delta R^{2}}$ & $\beta$ & & & $\Delta R^{2}$ & $\beta$ & & \\
\hline Step 1 & $<.01$ & & & & $<.01$ & & & & $<.01$ & & & \\
\hline Gender & & .04 & & & & .04 & & & & -.02 & & \\
\hline Step 2 & .04 & & & & $.06 *$ & & & & .01 & & & \\
\hline $\mathrm{FF}$ & & $.15^{*}$ & & & & -.04 & & & & -.03 & & \\
\hline $\begin{array}{l}\text { FE } \\
\text { UCLA }\end{array}$ & & $\begin{array}{l}-.15^{*} \\
-.02\end{array}$ & & & & $\begin{array}{l}.20 * * \\
-.12\end{array}$ & & & & $\begin{array}{r}.10 \\
<.01\end{array}$ & & \\
\hline Step 3 & $.05^{* *}$ & & & & $<.01$ & & & & .02 & & & \\
\hline $\begin{array}{l}\text { UCLA x } \\
\text { FF }\end{array}$ & & -.09 & & & & -.06 & & & & -.12 & & \\
\hline $\begin{array}{l}\text { UCLA x } \\
\text { FE }\end{array}$ & & $.25^{* *}$ & & & & .03 & & & & -.13 & & \\
\hline Total $R^{2}$ & & & & & & & & & & & & \\
\hline
\end{tabular}

